\title{
PLACING LANGUAGE IN THE FOREGROUND: THEMES AND METHODS IN INFORMATION TECHNOLOGY DISCOURSE
}

Eleanor H. Wynn

Intel Corporation

U.S.A.

Edgar A. Whitley London School of Economics and Political Science

United Kingdom

Michael D. Myers

University of Auckland

New Zealand

\section{INTRODUCTION}

We are pleased to bring you this volume of papers prepared for the IFIP Working Group 8.2 Conference held in Barcelona in December 2002. The subject of organizational discourse about information technology, and its counterpart, the discussion of technology as part of globalization, have been constant themes in Information Systems (IS) and within IFIP Working Group 8.2 for many years. However, this is the first time that discourse has been the explicit focus of an IFIP Working Group 8.2 conference, and only the second or third time that discourse has been the focus of a conference about Information Systems.

Yet one of the most inevitable features of the IS field is how quickly the discourse changes, as earlier technologies and practices disappear and as new possibilities become available. We need look back only a few years to discover themes that now seem passé, or terms whose meaning has changed dramatically since they were first discussed. Business process reengineering, for instance, is one such theme that emerged in the 1990s, but has since lost cachet. In some cases, the new frame of reference disappears into everyday practice, or adopts new subtexts. In other cases, issues become absurd. The imagined role of status in blocking male managers' adoption of personal computing is one such nonissue because of the clerical implications of typing. It was current in the early

The original version of this chapter was revised: The copyright line was incorrect. This has been corrected. The Erratum to this chapter is available at DOI: 10.1007/978-0-387-35634-1_28 
1980s and formed the basis for research on the touch screen. But it seems silly now. Of course, typing has become "keyboarding" partly as a response to that imagined threat. "Human resistance to change" has always been a favorite bogus phrase to the anthropologist working within IS, where we see people changing their practices at a rapid pace. Indeed, history contains many waves of sudden change resulting from new technology, changing resources, movement of people, or all of these. Terms such as e-commerce or e-business were unheard of in the IS research and practitioner literature at the beginning of the previous decade, but nowadays it would be impossible to find any introductory IS textbook that does not discuss these terms in great detail.

Regardless of the merits of any given term or thread of logic, the discourse becomes embedded and constrains investment and implementation decisions about new technology. As systems are built, used, rebuilt, or withdrawn, new inventions arise making old systems obsolete and new needs apparent. Every time this happens, decision makers draw on an implied model of their organization and its values, as well as of human behavior in general. In the case of the discourse about globalization and technologies for economic development, the assumptions become even broader, encompassing societal values, development models and trajectories, and the means of fostering democracy, literacy, and human well-being.

There at two main distinctions to be drawn. One is the actual terminology commonly used to describe either a technology or the organizational "problem" that it solves. The other is the dialogue process by which decisions are reached and influence exercised. Dialogue not only traces the reasoning process, the lines of argument, and the language used to describe sensitive issues. It also reflects the actor-network aspect of terms, tokens, solutions, relationships, compromises, and the objects that embody them and form the outcome of the dialogue. In short, the enacted technological implementation is the product of a conversation and then, as it acquires mass and substance and is embedded in everyday business practice or economic life, forms the context of a new conversation.

Many organizations are now coping with expected changes arising from virtuality, such as distributed work teams, enterprise-wide content access and expertise location, and new forms of distance expressivity. This effort impinges greatly on the social context of work. Concurrently, large corporations face major paradigm shifts arising from dramatic economic changes, globalized workforces and heightened concerns about information and asset security. As they seek to prepare for the many possible eventualities on the horizon, they may remain bound by a dialogue whose limitations were a luxury of simpler times. Institutional reflection about the nature of the organization or of organized human activities in general has a hard time keeping up with ever newer capabilities, like peer-to-peer computing, ubiquity, and self-organizing technical systems, let alone the notions of self-organizing social systems or actor networks. 


\section{BACKGROUND}

The formal study of naturally occurring discourse dates only to the $1960 \mathrm{~s}$, although examination of the implications of language is one basis for all Western philosophy. Linguistic anthropologists of the $19^{\text {th }}$ century actually "gathered" languages from people they studied, writing grammars and dictionaries to preserve them and use them in the general study of language. In the 1960s, linguistic anthropologists like Dell Hymes and John Gumperz turned as well to the study of language in use. Gumperz and Hymes defined the field of sociolinguistics, emphasizing the role of context in the interpretation of meaning, and defining the "speech event" which is a key feature of context. In this view, meaning can only be determined by first understanding the cultural "event" within which words are spoken. This removed language analysis from the strict study of syntax and semantics and stated that meaning cannot be determined without convention and context. This also took the emphasis away from language universals and more toward the particularities of social context. Most of these contexts were put into named categories, like casual conversation, chit-chat, argument, lecture, or joke. Searle added to this the notion of implicature, whereby relationships among people can be derived from the "performatives" inferred from a given utterance. "I need new clothes" constitutes a different speech act depending on whether it spoken by a teenager to a parent or by a teenager to a friend. In the first case, the utterance, as a speech act, is a request. In the second, it is simply a declarative statement.

Ethnomethodology, developed by Harold Garfinkel, Harvey Sacks, and Emanuel Schegloff and supported by the fascinating phenomenological observations of Erving Goffman, employed language-in-use as the basis for understanding how social convention is actually structured within the framework of talking. These theorists asserted that it is within the ongoing discourse, on each and every occasion, that social meaning is continually constructed along with the social order it represents. Frankfurt school theorists also fit into this line of thinking. The things that don't need to be stated are in fact the clues to what is underlying and the basis of the assumptions shared by conversants. In other words, discourse embodies the social structure as it continually either reproduces or transforms it

The work of one of our keynote speakers, Lucy Suchman, originated in this tradition. Her work illustrates the approach well, applying it to the present context of organization and information technology. Going back to Hymes, and also the groundbreaking quantitative phonological work of William Labov, we also gained the concept of a social repertoire and a repertoire range. This topic has been echoed in the work of Orlikowski on genre, as an accounting not only of the genre formats but as a framework for social choice implied in them. Labov's work illustrated that people shifted their phonology from vernacular to formal according to the context. It posited a social dimension in the change of 
phonology over time, generally in the direction of upper class speech, although with the advent of rap we see an opposite direction, an adoption by middle class youth of a strong subcultural vernacular.

In any event, there is an implication of rank and power in the choice of words, speech style, and genre. That is why Lynne Markus' classic paper in Communications of the ACM (Markus 1983) struck such a chord and launched, in some ways, the critical study of IS implementations. Maurice Bloch's (1975) seminal book entitled Political Language and Oratory in Traditional Society set an empirical foundation, reflected in Foucault's work, of exactly how speech events and their compelling structures can be used to enforce power in any given situation. There are times when asking questions or insisting on definitions is seen as an open display of rebellion and a challenge to power. In this vein, the work of Habermas is well known within the IFIP WG 8.2 community. The work of Heidegger informed ethnomethodology, which shows in great detail the mechanism of constructing the world in language.

The goal of this conference is to provide an opportunity for reflections like those above as an explicit undertaking for the IS field. What assumptions are hidden in our talk about plans for change? What forms of discourse mask or create confusion rather than clarify issues? What part of our conversation about technology is a posture rather than an open examination? And in the end, how far can we question convention without losing the comforts of order and predictability? This line of inquiry draws on some noble predecessors in the social sciences and philosophy. We feel that it is important to make such reflection available to the practitioner, who is burdened with choices, but whose life of deciding is too engaging to allow time to think about the meaning of things. Yet from time to time the meaning of things becomes the question of the hour. We believe that an example is the best way to convey the message of these formative ideas, as examples are easier to recall than the logic of Heidegger or Habermas. Indeed, too deep a thought process is prone to subversion into jargon and misconstrual, where the terms are employed but, being too hard to bring into everyday plans, serve only as symbols while the operational thinking remains unaffected. We believe that these conference papers will illuminate theory with relevant examples.

It is appropriate in the context of this brief review of influences to acknowledge the profound contribution of Kristen Nygaard, who passed away recently. Kristen introduced the concept of social context and vernacular language into computer science and information systems by being the early adopter of relevant research. He widely circulated Wynn's photocopied 1979 dissertation throughout Scandinavia as an example of how to address labor advocacy questions in system development process. He also fostered the work of Suchman and employed Norwegian linguistic anthropologists for the development of his programming language, Simula. Many, if not most, of the current, distinguished Scandinavian members of WG 8.2 were students or grand-students of Kristen's. 
To him we credit the bridging of computing and social thinking and dedicate this conference.

\section{THE REVIEW PROCESS}

A total of 60 papers and panel proposals were submitted to the conference organizers. The papers were submitted from all over the globe, with 15 papers from AIS region 1 (the Americas), 44 from AIS region 2 (Europe, Middle East, and Africa), and 8 from AIS region 3 (Asia and the Pacific). Although a number of papers featured authors from more than one institution, only two submissions (other than panels) featured authors from more than one AIS region.

The submissions were allocated to the three program chairs who managed the review of 20 papers each. Care was taken to ensure that program chairs and reviewers were not involved with the reviews of close colleagues or friends. Each paper was allocated three reviewers who were drawn from the authors and the program committee, with members of the program committee doing up to three reviews each and authors doing one. Access to the papers and submissions of the reviews was done electronically over the Web and, after a few minor teething problems, worked exceedingly well. The Web based system allowed the review managers to keep track of their remaining reviews as well as preparing the final reviews that were sent to the authors. The system also enabled all reviewers to receive copies of all the reviews for the papers with which they were associated.

After careful consideration of the extensive reviews provided by the members of the Program Committee and the reviewers, we accepted 22 papers and three panel proposals for the conference (an acceptance rate for research papers of just under $40 \%$; however, one author subsequently withdrew his paper from the conference). Two keynote speakers were also invited to give plenary presentations. The profile of the accepted papers maps closely onto that of the submitted papers.

\section{OVERVIEW OF THE PAPERS}

In the remainder of this chapter, we provide an overview of the accepted papers. They are grouped according to the sessions in the conference program. The papers cluster into two rough groups: those more focused on theory and those that are more applied to a particular situation or context. We came up with three subdivisions in the theoretical category: analytical frameworks (two sessions), critical research, and mobilization of power. In the applied or 
descriptive category we have five general themes: IS planning and projects, globalization, development and space, ERP systems, and public institutions. In addition, three panel sessions were accepted for inclusion in the conference.

\subsection{The Keynotes}

Our distinguished keynote speakers approach the conference theme of global and organisational discourse about information technology in distinct ways. Burt Swanson's paper, "Talking the IS Innovation Walk," draws on his experiences with trying to understand how organisations come to frame and describe their new technology innovations. He is particularly interested in how buzzwords and other devices of discourse shape the diffusion of innovations in organizations.

In contrast, Lucy Suchman's paper, "Figuring Service in Discourses of ICT: The Case of Software Agents," draws on her ground-breaking research into how humans and technology interact to study the figurative ways in which software agents are described and ascribed human-like abilities. In so doing, the discourses tend to hide the complexities of the many human activities they are designed to support.

\subsection{Analytical Frameworks}

There are two sessions in the analytical frameworks category. The first paper, by Roberta Lamb and Mark Poster, is entitled "Transitioning Toward an Internet Culture: An Interorganizational Analysis of Identity Construction from Online Services to Intranets." In this paper the authors take a closer look at the transition from "older" media and technologies to the Internet. They suggest that creative uses of older media, like online profiling, have set the stage for common uses of the new media (the Internet). Constrained uses of Internet technologies, like intranets and extranets, allow corporations and governments to extend control over self-presentations and to more effectively interpellate identities.

The second paper, by Mats Edenius, entitled "Discourse on E-Mail in Use," looks at what the author considers to be the contemporary key features of the discursive formations around e-mail in a professional context. He suggests that we do not have to take the dominant discursive formations for granted.

Bernd Stahl, in his paper entitled "When Does a Computer Speak the Truth? The Problem of IT and Validity Claims," explores the question of whether the use of computers affects the perceived truth value of statements. He discusses his question using the theory of truth and validity claims put forward by Habermas. 
The fourth paper in this category is by Steve Sawyer and Tina Chen. Entitled "Conceptualizing Information Technology in the Study of Information Systems: Trends and Issues," this paper looks at the conceptualization of information and communication technologies (ICT) as portrayed in the contemporary IS research literature. Comparing two important outlets for IS research, they found significant differences in the conceptualization of ICT.

The fifth paper, by Gus Hosein, is entitled "A Research Note on Capturing Technology: Toward Moments of Interest." Hosein argues that, while IS research has placed technological determinism to rest, in so doing it has either taken the technology for granted, or replaced it with social forces. He suggests a way to reintroduce the technological to our social explanations by outlining a research approach for capturing the technological at moments of interest.

The final paper in this category is by Lucas Introna and Louise Whittaker. Entitled "The Phenomenology of Information Systems Evaluation: Overcoming the Subject/Object Dualism," the authors argue that the path to "better" IS evaluation in organizations is to get beyond the dualisms of subject/object, mind/ body, and cognition/action that limit our analysis, understanding, and practice of evaluation in the flow of organizational life. They present a discussion of the unity of cognition and action using the work of phenomenologists such as Bergson, Heidegger, Merleau-Ponty, Henry, and James.

\subsection{Critical Research}

The first paper in the critical research category is Dave Wastell's paper, entitled "Organizational Discourse as a Social Defense: Taming the Tiger of Electronic Government." In this paper, Wastell looks at the social defensive role of discourse as a device for constructing a sense of self and as a means for warding off task-related anxiety. He does so by examining a study of egovernment discourse in a local government organization in the United Kingdom.

The second paper, by Wendy Cukier, Catherine Middleton, and Robert Bauer, and is entitled "The Discourse of Learning Technology in Canada: Understanding Communication Distortions and Their Implications for Decision Making." In this paper, the authors examine the societal discourse on technology in education in Canada from 1993 to 1998. They assess communications distortions guided by Habermas' standards of "validity claims" for communications: truth, clarity, sincerity and legitimacy. 


\subsection{Mobilization of Power}

In her paper entitled "Rhetoric of Enrollment and Acts of Resistance: Information Technology as Text," Melanie Wilson describes the metaphor of "the technology as text" as proposed by social shaping of technology approaches. She examines the problem of taking for granted the success of the mobilizations of power involved in representation practices. She illustrates this with a case study of hospital information systems.

The second paper, by Emmanuel Monod, Duane Truex, and Richard Baskerville, is entitled "The Discourse of a Large Scale Organizational Transformation: The Reengineering of IBM, 1989-1994." In this paper, the authors examine an organizational discourse on radical transformation by identifying and analyzing management narratives claiming to be representative of different organizational stakeholders.

The third paper is by Lynette Kvasny and Eileen Trauth. Entitled "The Digital Divide at Work and Home: Discourses About Power and Underrepresented Groups in the Information Society," the authors conducted a critical analysis of discourses about power and IT. Based upon the findings from a study of power and IT among African-American men and women in low income urban communities, a framework was applied to the findings of two studies of gender in the IT profession.

\subsection{IS Planning and Projects}

The first paper in this category is by Mike Metcalfe and Maureen Lynch. Entitled "Arguing for Information Systems Project Definition," the authors discuss argumentation as an inquiry method and argue that argumentation is useful for project definition. In support they present evidence from 14 six-month information systems projects.

The second paper is by Chris Atkinson. Entitled "The Nature and Role of Generative Systemic Metaphor within Information Systems Planning and Development," the author discusses a number of systematic metaphors that are used to underpin the discourses and methodologies associated with the planning and development of information systems.

\subsection{Globalization, Development, and Space}

In his paper entitled "ICT, Power, and Developmental Discourse: A Critical Analysis," Mark Thompson uses critical discourse analysis to demonstrate how 
information and communications technologies have become deeply involved in the conception and practice of socio-economic development within so-called less developed countries.

Pamela Abbott and Matthew Jones, in their paper entitled "The Importance of Being Nearest: Nearshore Software Outsourcing and Globalization Discourse," critique the idea of the "death of distance." They question the notion that globalization inevitably leads to "placelessness" and homogeneity and suggest that the nation state may well remain an important influence on economic activity.

\subsection{Enterprise Resource Planning}

The first paper in this section is by Chris Westrup. Entitled "Discourse, Management Fashions, and ERP Systems," the author critiques the notion of discourse as the sole means to apprehend the world. He uses the notion of management fashion as an example of a discourse based approach to explore the rise and apparent demise of ERP systems. He suggests that the idea of articulation is a more useful way to explain the mechanisms by which relations are constructed, sustained, and fall away in the organizing of technologies such as ERP systems.

The second paper, by Erica Wagner, is entitled "Interconnecting Information Systems Narrative Research: An End-to-End Approach for Process-Oriented Field Studies." The author argues that adopting a narrative approach to processoriented field research can provide multiple insights about computer-mediated change initiatives. The particular narrative approach presented in the paper is illustrated through a narrative study of an ERP software project within an Ivy League university.

Jeremy Rose and Pernille Kræmmergaard, in their paper entitled "Dominant Technological Discourses in Action: Paradigmatic Shifts in Sense Making in the Implementation of an ERP System," discuss the implementation of an ERP system in a large Danish production company. They show that the ways in which the participants made sense of the project changed appreciably during the course of the project.

\subsection{Public Institutions}

Public institutions such as health service providers and universities constitute a rich area for undertaking research that differs in important ways from large, traditional organizations. The papers in this section explore the particular discourses that arise in public institutions. 
The first paper, by Gunnar Ellingsen, entitled "Knowledge Work in Hospitals" explores the discourses about the management and reuse of knowledge in a Norwegian hospital that arise in the work of physicians providing discharge reports for patients. The organizational complexity of the hospital setting combines with questions of trust and uncertainty in shaping these activities.

The paper "In a Mood to Make Sense of Technology: A Longitudinal Study of Discursive Practices at the London Ambulance Service" by Kathy McGrath is also located in the health sector, but here the author examines the tensions within the London Ambulance Service when it launched a new information system with memories of a previous, failed system still shaping people's perceptions.

"ERP Adoption: Selling the System" by Dave Oliver and Lyn Oliver provides a critical discourse analysis of the announcement of a new enterprise system in an Australian university. It shows how language sets up both the problems with the existing system and the need for the new system while trying to ensure ownership of the project implementation.

\subsection{Panels}

Most of the papers for the conference take discourse as being a textual and linguistic phenomena. The panel by Mark Ackerman, Brian Pentland, Sajda Qureshi, and Elaine Yakura instead looks at the visual aspects of discourse, emphasizing that both the technology we talk about and the ways we talk about it are becoming increasingly visual with graphical as well as textual elements.

In contrast, the panel by Michael Barrett, Loizos Heracleous, Wanda Orlikowski, and Niki Panteli looks at how more traditionally language-based discourse can be used to study technology enabled organizational change and virtual organizing. By drawing on various research traditions, the panel shows how language creates and sustains organizations.

The third panel, featuring Bonnie Kaplan, Lynette Kvasny, Steve Sawyer, and Eileen Trauth, challenges us to look beyond traditional organizations when studying IS discourse and focus on different kinds of organizations and levels of analysis. The aim is that by looking at other discourses, we can push the IS field forward.

\section{CONCLUSIONS}

With this conference our intention was to place language in the foreground of our research agenda on information technology and systems. We hope this 
volume opens up many new themes and methods in the ongoing discourse about ICT and its use in social and organizational contexts.

\section{REFERENCES}

Bloch, M. (ed.). Political Language and Oratory in Traditional Society. New York: Academic Press, 1975.

Markus, M. L. "Power, Politics and MIS Implementation," Communications of the ACM (26:6), 1983, pp. 430-444.

\section{About the Authors}

Eleanor H. Wynn works in Intellectual Capital within Information Technology at Intel Corporation. She received a Ph.D. in Linguistic Anthropology from the University of California, Berkeley. She initiated the practice of language analysis for understanding workplace practices at Xerox PARC as a graduate student in 1976. Since then, she has worked both in industry and universities. She has published on a wide range of topics relating to the role of social interaction and social groups in Information Systems planning, development, and use. She has been editor-in-chief of Information Technology \& People since 1985, a role she now shares with Edgar Whitley. Her work at Intel is focused on virtuality and actor networks as a model for an adaptive organization. Eleanor can be reached by e-mail at eleanor.wynn@intel.com.

Edgar Whitley is a senior lecturer in Information Systems at the London School of Economics and Political Science. He has a B.Sc. (Econ) Computing and a Ph.D. in Information Systems, both from the LSE. He has taught undergraduate and postgraduate students and managers in the United Kingdom and abroad. Edgar was one of the organizers of the First European Conference on Information Systems and is actively involved in the coordination of future ECIS conferences. He has recently been appointed coeditor for Information Technology \& People and edited, with Heejin Lee, a special issue of The Information Society on Time and Information Technology. Edgar can be reached by e-mail at E.A.Whitley@1se.ac.uk.

Michael D. Myers is Professor of Information Systems in the Department of Management Science and Information Systems at the University of Auckland, New Zealand. He currently serves as a senior editor of MIS Quarterly, an associate editor of Information Systems Research, editor of the ISWorld Section on Qualitative Research, and editor of the University of Auckland Business Review. He also serves as Vice Chair of IFIP Working Group 8.2. His research articles have been published in many journals and books. He won the Best Paper 
award (with Heinz Klein) for the most outstanding paper published in MIS Quarterly in 1999. He also won the Best Paper Award (with Lynda Harvey) for the best paper published in Information Technology \& People in 1997. Michael can be reached by e-mail at m.myers@auckland.ac.nz. 